\title{
Atmospheric Corrosivity Estimation at Electrical Control Unit Room by Multichannel Quartz Crystal Microbalance Corrosion Sensors
}

\author{
Kazumi Fujii ${ }^{1}$, Kenya Ohashi $^{1}$, Tadahiko Hashimoto ${ }^{2}$ and Nobuyoshi Hara ${ }^{3}$ \\ ${ }^{1}$ Department of Materials Research for Power Plants, Hitachi Research Laboratory, Hitachi, Ltd., Hitachi 319-1292, Japan \\ ${ }^{2}$ Information and Control Systems Division, Hitachi, Ltd., Hitachi 319-1293, Japan \\ ${ }^{3}$ Department of Materials Science, Graduate School of Engineering, Tohoku University, Sendai 980-8579, Japan
}

\begin{abstract}
In order to evaluate the atmospheric corrosivity in an electrical control unit room in a steelmaking plant by using quartz crystal microbalance (QCM) sensors, the temperature, relative humidity and corrosion rates of metals on QCM were monitored for five months. The metals employed for sensing corrosive gases were silver, copper and cobalt. The concentrations of the corrosive gases were estimated from the data of corrosion rates for these metals considering relative humidity. The temperature, relative humidity, and the corrosion rates in a given day were distributed according to the normal probability law. The concentrations of $\mathrm{H}_{2} \mathrm{~S}, \mathrm{SO}_{2}$ and $\mathrm{NO}_{2}$ were estimated from the mean values of the relative humidity and the corrosion rates of silver, copper and cobalt, which derived from the normal probability plots. The concentrations thus obtained were roughly close to those analyzed by conventional analytical methods. The atmospheric corrosivity will be able to estimate based on the monitoring of the corrosion rate with multichannel QCM sensors. [doi:10.2320/matertrans.M2011238]
\end{abstract}

(Received August 9, 2011; Accepted November 17, 2011; Published January 18, 2012)

Keywords: electrical control unit, temperature, relative humidity, corrosion rate, silver, copper, cobalt, quartz crystal microbalance, inverse estimation, hydrogen sulfide, sulfur dioxide, nitrogen dioxide, normal probability distribution

\section{Introduction}

The service environment of the electrical control unit in a factory contains corrosive gas that is generated in manufacturing process occasionally. The traffic monitoring system might be suffered automobile exhaust emission. These electronic and electric facilities must work stably for a long time. When a metallic component in such equipments is damaged by corrosion, malfunctioning or failure might occur. In the standards issued by the Japanese Industrial Standards (JIS) ${ }^{1)}$ the International Electrotechnical Commissions (IEC), ${ }^{2)}$ and the Japanese Electronic Industry Development Association (JEIDA), ${ }^{3)}$ the severity of a corrosive environment is classified according to the concentration of corrosive gas species in the atmosphere. On the other hand, the standard issued by the Instrument Society of America (ISA) ${ }^{4}$ defines the severity of environments on the basis of the rate of corrosion on a copper test piece measured in the environment.

The evaluation of the severity of corrosive environments for electronic and electric equipments is sometimes carried out by analyzing specific gases in the air sampled. However, it is sometimes the case that the severity of the evaluated corrosive environment does not correspond well to the detected degree of the corrosion damage. For instance, a copper migration occurred although the atmosphere in the electrical control room of a steelmaking plant was moderately corrosive. ${ }^{5)}$

By combining a quartz crystal microbalance $(\mathrm{QCM})^{6)}$ and gas analyzer, Forslund et al. ${ }^{6}$ ) monitored the atmospheric environment in the paper manufacturing plant and illustrated a correlation between the metallic corrosion rate and the corrosive gas concentration fluctuation pattern. On the other hand, Todo et al. ${ }^{7)}$ analyzed the correlation of measured copper corrosion with the atmospheric temperature, relative humidity, corrosive gas concentration, and airborne sea salt particle concentration. They confirmed the validity of the severity classification issued by JEIDA-63-2000 standard, ${ }^{3)}$ claiming that a reliable copper corrosion weight loss evaluation could be achieved referring to the JEIDA standard.

QCM is used for continuous in situ monitoring of metal corrosion in ambient atmosphere. In fact, QCM was used for metal corrosion monitoring at the telephone exchange room, ${ }^{8)}$ at electrical control unit room in steelworks plant, ${ }^{5)}$ and at the paper manufacturing plant. ${ }^{6)}$ In the past research, ${ }^{6)}$ the corrosion rate of the metal with QCM sensors and the corrosive gas concentrations were independently measured. Then corrosion environment was analyzed from the corrosion rate of the measured metal compared with the concentration of the corrosive gas. In a previous study, ${ }^{9)}$ the corrosion rates were monitored using QCM sensors containing different metal thin films in the well-controlled corrosive atmosphere chamber. And corrosion rate equations of metals as function of the corrosive species were derived from the regression analysis. Then, the corrosive gas concentration was inversely estimated from the corrosion rate equations.

The purpose of this study is to examine the possibility of evaluating the atmospheric corrosivity of actual electrical control unit room in a steelmaking plant with the reverse estimation for the gas concentration by the multichannel quartz crystal microbalance sensors.

\section{Experimental}

The monitoring system ${ }^{5)}$ consisting of QCM, temperature and humidity sensors were set up at an air-conditioned electrical control unit room in a steelmaking plant. Monitored data were gathered for five months from November 1998 to May 1999. The data were sampled at $6 \mathrm{~min}$ intervals and stored in the hard disk of a personal computer. The QCM sensor was made from an AT-cut quartz crystal substrate (supplied by Meidensha Corporation) with a diameter of $8 \mathrm{~mm}$ and a fundamental frequency of $10 \mathrm{MHz}$. Both sides of 

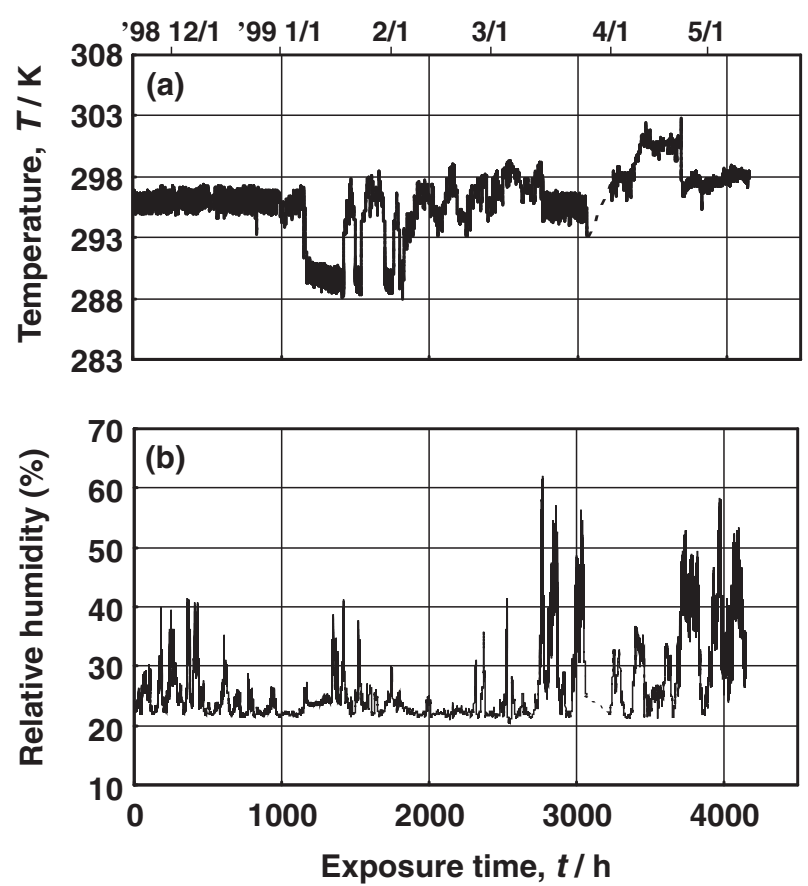

Fig. 1 Temperature (a) and relative humidity (b) changes in the monitoring period.

the quartz crystal substrates were deposited directly with silver, copper or cobalt thin films by radio frequency (RF) magnetron spattering. The sputtering equipment was supplied by Anelva (SPF-313H) and the sputtering target materials with $99.98 \%$ or $99.998 \%$ purity were supplied by the Kojundo Chemical Laboratory Co. Ltd. The chamber of the sputtering system was evacuated to the level lower than $2.0 \times 10^{-4} \mathrm{~Pa}$. After evacuation, a metal thin film was deposited with the thickness of about $300 \mathrm{~nm}$ by sputtering with RF power of $800 \mathrm{~W}$ at ambient temperature. The substrate temperature was not controlled. Then the quartz crystal with a sputter-deposited metal thin film was inserted in a lead socket supplied by Meidensha Corporation. Finally the electrical contact between the quartz crystal and the lead socket was ensured by applying $\mathrm{Ni}$ dispersed electroconductive adhesive supplied by ThreeBond (3381). The monitored frequency change was converted into the mass change using the Zauerbrey equation ${ }^{10)}$ and the corrosion rate was estimated from the evaluated mass change.

\section{Results and Discussion}

\subsection{Monitoring of temperature and relative humidity}

Figure 1 shows the temperature and relative humidity changes during the monitoring period. The temperature fluctuated between 288 and $303 \mathrm{~K}$, and most of the temperature ranged among 293-298 K. The temperature fluctuation was small in the initial $1000 \mathrm{~h}$ period, but became large and irregular after $1000 \mathrm{~h}$. It is thought that the fluctuation was caused by the penetration of outside air when the door was opened and temporary shutdowns of the air-conditioner. The mean temperature during the monitoring period was $296.3 \mathrm{~K}$ and the maximum temperature was $303.0 \mathrm{~K}$. The relative humidity ranged 20 to $60 \%$. It was mostly less than $30 \%$, but sometimes showed a spike-like change. After $2500 \mathrm{~h}$, the

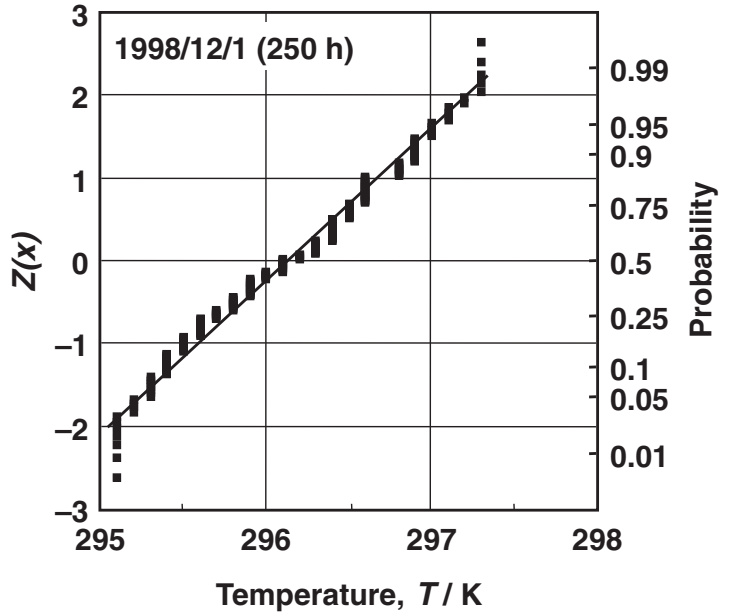

Fig. 2 Normal probability plot of temperature at 1998/12/1 (250 h).

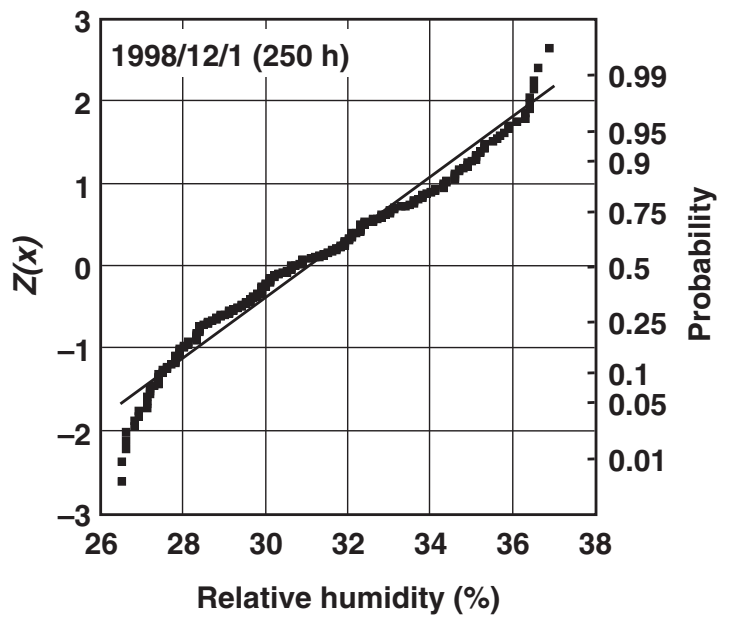

Fig. 3 Normal probability plot of relative humidity at 1998/12/1 (250 h).

spikes in the relative humidity rises appeared frequently. The mean relative humidity during the monitoring period was $26.4 \%$ and the maximum was $62 \%$. In the previous study, it was found that the monthly average temperature was distributed according to the normal probability law for the past 30 years. ${ }^{11)}$ Therefore it was attempt to plot measured data of temperatures and humidity as normal probability distribution.

Figure 2 shows the normal probability plot of the temperature for one day, December 1st, 1998 (After almost 250 h pass). There are 240 data points. The temperature was distributed according to the normal probability law, and the mean temperature was $296.3 \mathrm{~K}$. Figure 3 shows the normal probability plot of the relative humidity on the same date as Fig. 2. The relative humidity was roughly distributed according to the normal probability law, and the mean relative humidity was $31.1 \%$. Since the changes of the temperature and the relative humidity for other days fitted to the normal probability plots in a similar manner as Figs. 2 and 3. Shinohara et al. ${ }^{12)}$ reported that temperature and relative humidity were distributed according to the normal probability distribution for two years at a building located in a seashore area in Chiba prefecture, Japan. Because the 


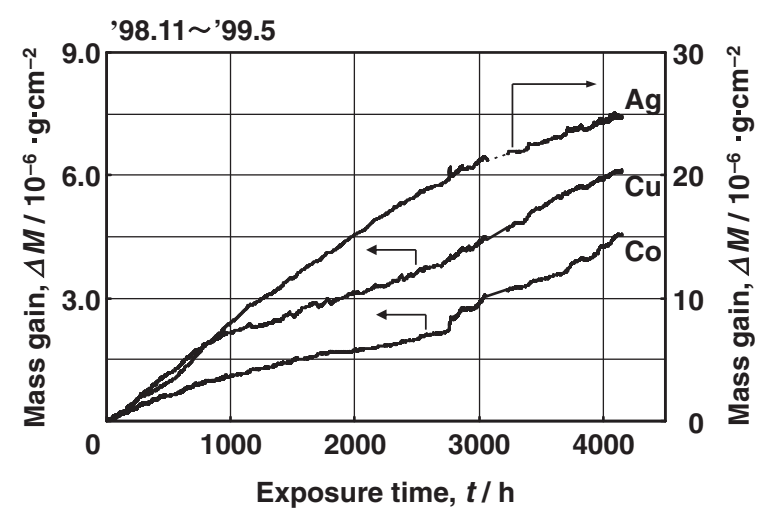

Fig. 4 Mass gains on QCM sensors of silver, copper and cobalt in the monitoring period.

temperature and humidity showed similar distribution, it was concluded that the normal probability plots was useful to obtain the mean temperature and humidity for given day through the monitoring period.

\subsection{Quartz crystal microbalance monitoring}

The mass gain of silver, copper and cobalt films was derived from frequency changes of QCM sensors during the monitoring period.

Figure 4 shows the changes in the mass gain as a function of exposure time. The measured mass gain represents the sum of the weight of the corrosion products of the metal, the dust particles deposited on the sensor surface, and water adsorbed on the surface. In the following analysis, it was considered that the influences of the other factors except for the corrosion products are constant and thus the increase in the measured mass gain is due to the increase in the mass of corrosion products. The total mass gain through the monitoring period was estimated to be $2.5 \times 10^{-5} \mathrm{~g} \cdot \mathrm{cm}^{-2}$ for Ag, $6.0 \times 10^{-6} \mathrm{~g} \cdot \mathrm{cm}^{-2}$ for $\mathrm{Cu}$, and $4.5 \times 10^{-6} \mathrm{~g} \cdot \mathrm{cm}^{-2}$ for $\mathrm{Co}$. Figure 5 shows the corrosion rate for silver (a), copper (b) and cobalt (c) evaluated from the mass gain for every $24 \mathrm{~h}$. The corrosion rate here is defined as an increase rate of the mass of the corrosion products. The maximum corrosion rate was $3.33 \times 10^{-8} \mathrm{~g} \cdot \mathrm{cm}^{-2} \cdot \mathrm{h}^{-1}$ for silver, $1.11 \times 10^{-8}$ $\mathrm{g} \cdot \mathrm{cm}^{-2} \cdot \mathrm{h}^{-1}$ for copper and $1.48 \times 10^{-8} \mathrm{~g} \cdot \mathrm{cm}^{-2} \cdot \mathrm{h}^{-1}$ for cobalt.

Figures 6, 7 and 8 show normal probability plots of the corrosion rate for silver, copper and cobalt on December 1st, 1998. The corrosion rate for each metal was roughly distributed according to the normal probability law. The mean corrosion rates were $1.16 \times 10^{-8} \mathrm{~g} \cdot \mathrm{cm}^{-2} \cdot \mathrm{h}^{-1}$ for silver, $3.59 \times 10^{-9} \mathrm{~g} \cdot \mathrm{cm}^{-2} \cdot \mathrm{h}^{-1}$ for copper and $2.09 \times 10^{-9}$ $\mathrm{g} \cdot \mathrm{cm}^{-2} \cdot \mathrm{h}^{-1}$ for cobalt. The distribution of the corrosion rate analyzed for other days also obeyed the normal probability law.

\subsection{Estimation of the atmospheric corrosivity}

As the relative humidity and corrosion rate were distributed according to the normal probability distribution, the mean values for the relative humidity and the corrosion rate of each metal for a given day were estimated from the normal probability plots. Figure 9 shows the change of the daily mean values for relative humidity and the corrosion rates as a

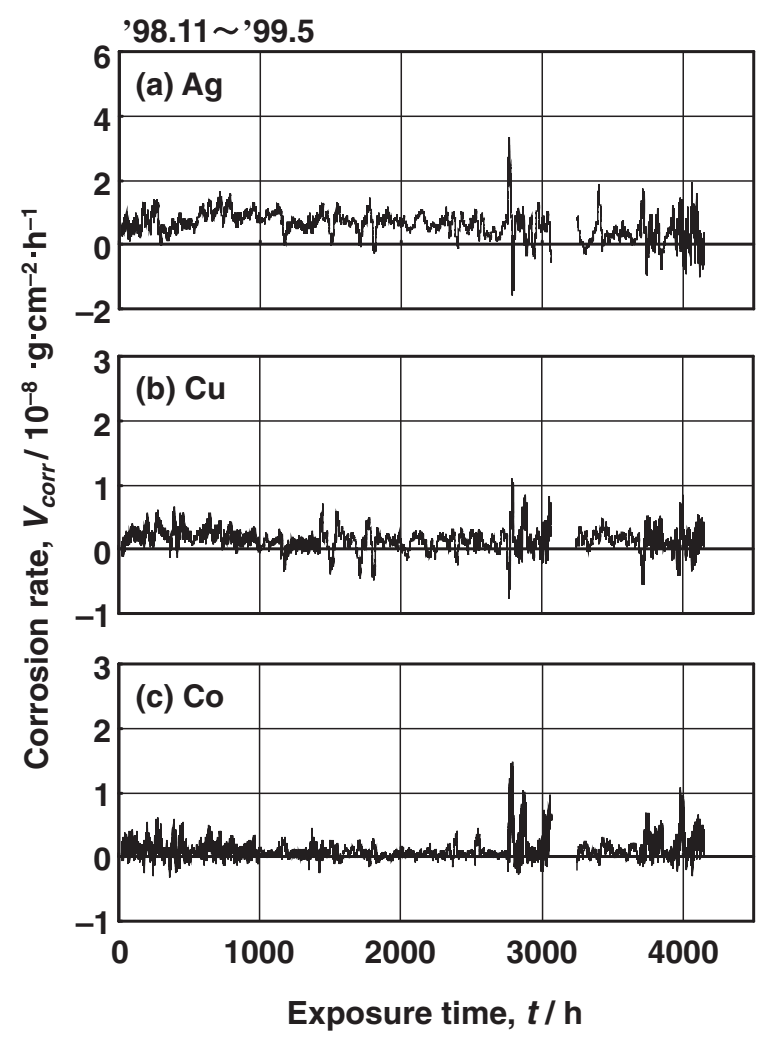

Fig. 5 Corrosion rate changes on QCM sensors of silver (a), copper (b) and cobalt (c) in the monitoring period.

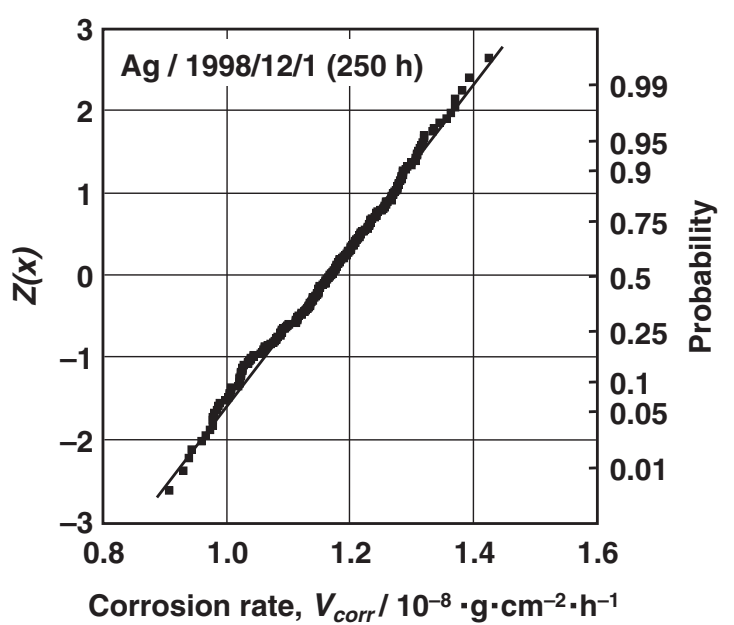

Fig. 6 Normal probability plot of corrosion rate on QCM sensor of silver at 1998/12/1 (250 h).

function of exposure time. The corrosion rate of cobalt seems to have changed corresponding to the change in relative humidity excluding a part of data, while the corrosion rates of silver and copper are thought to have changed independent of the change in relative humidity. In the previous study, ${ }^{9)}$ it was found that the corrosion rates of silver and copper are independent of the relative humidity. The corrosion rate of silver depends on the corrosive gas concentration of nitrogen dioxide and hydrogen sulfide, and that of copper on the concentration of sulfur dioxide and hydrogen sulfide.

From these statistical evaluations, it is possible to assume that the corrosion rate changes not only with the relative 


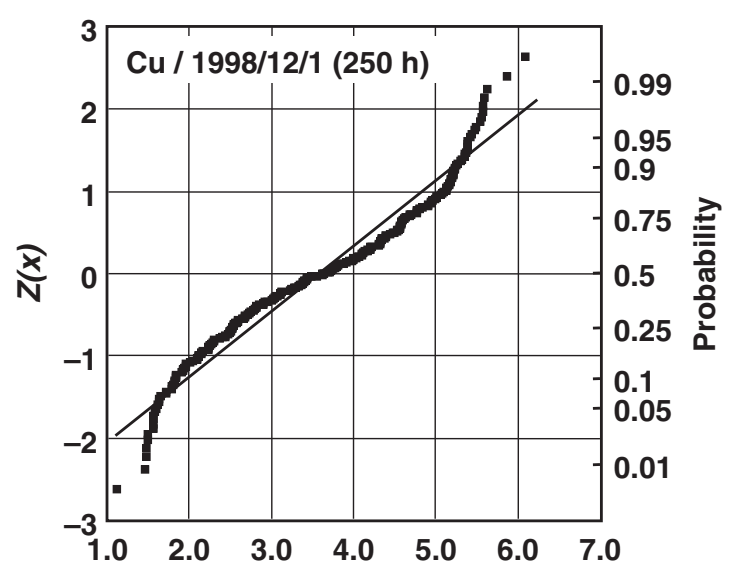

Corrosion rate, $V_{c o r r} / 10^{-9} \cdot \mathrm{g} \cdot \mathrm{cm}^{-2} \cdot \mathrm{h}^{-1}$

Fig. 7 Normal probability plot of corrosion rate on QCM sensor of copper at $1998 / 12 / 1(250 \mathrm{~h})$

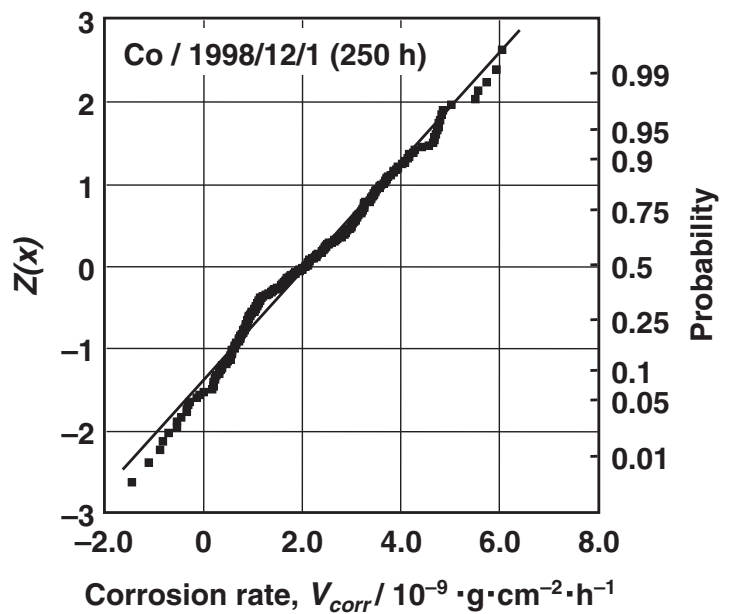

Fig. 8 Normal probability plot of corrosion rate on QCM sensor of cobalt at $1998 / 12 / 1(250 \mathrm{~h})$.
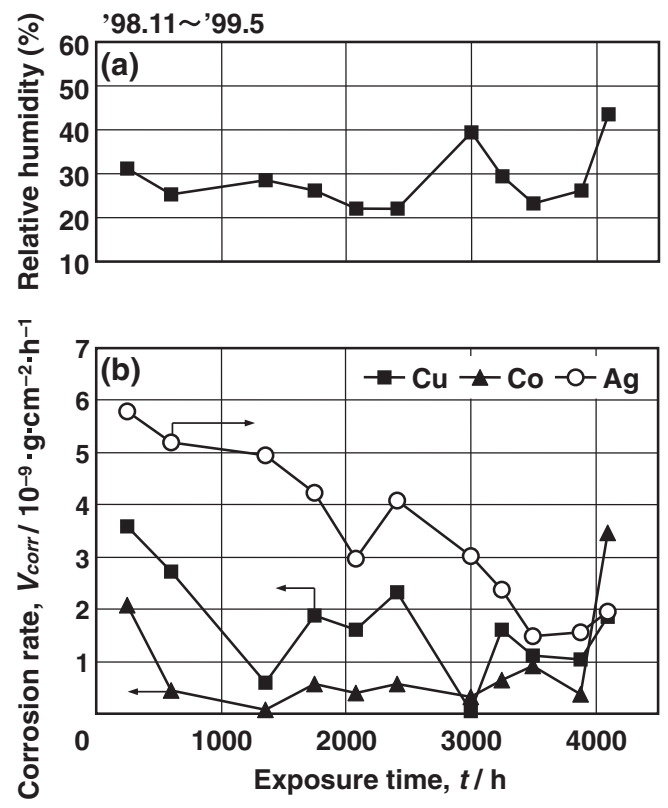

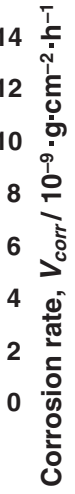

Fig. 9 Relative Humidity (a) and Corrosion rate (b) changes in the monitoring period.

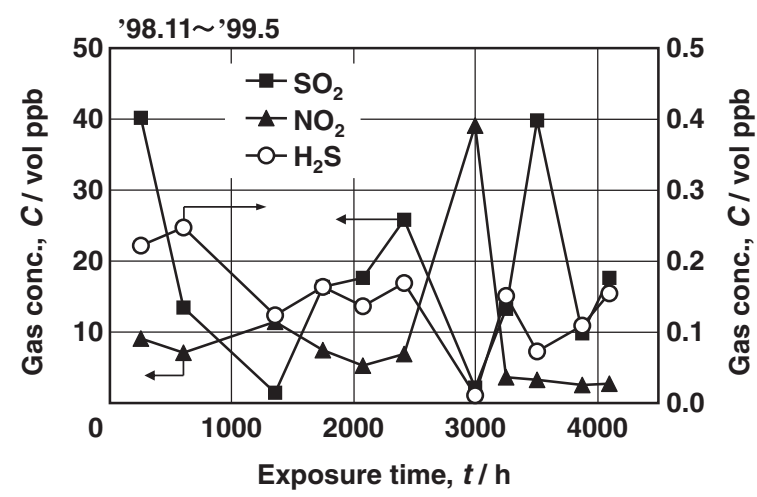

Fig. 10 Gas concentration changes in the monitoring period.

humidity but also with the corrosive gas concentration. In order to estimate the concentration of the corrosive gas from the corrosion rate and relative humidity, the following equations derived from the regressions for the corrosion rates of metals in well-controlled corrosive atmospheres at $298 \mathrm{~K}^{9)}$ can be used:

$$
\begin{aligned}
\log \left[C_{\mathrm{H}_{2} \mathrm{~S}}\right]= & 0.962 \times \log \left[R_{\mathrm{Cu}}\right]-0.380 \times \log \left[R_{\mathrm{Co}}\right] \\
& +1.660 \times[\mathrm{RH} / 100]-1.942 \\
\log \left[C_{\mathrm{SO}_{2}}\right]= & 1.108 \times \log \left[R_{\mathrm{Co}}\right]-4.840 \times[\mathrm{RH} / 100] \\
& +2.0648 \\
\log \left[C_{\mathrm{NO}_{2}}\right]= & 1.372 \times \log \left[R_{\mathrm{Ag}}\right]-0.752 \times \log \left[R_{\mathrm{Cu}}\right]+0.297 \\
& \times \log \left[R_{\mathrm{Co}}\right]-1.29 \times[\mathrm{RH} / 100]-0.423
\end{aligned}
$$

where $\left[C_{\mathrm{H}_{2} \mathrm{~S}}\right],\left[C_{\mathrm{SO}_{2}}\right]$ and $\left[C_{\mathrm{NO}_{2}}\right]$ refer to the concentration of hydrogen sulfide, sulfur dioxide and nitrogen dioxide in $\mu \mathrm{g} \cdot \mathrm{m}^{-3}$ respectively. $\left[R_{\mathrm{Cu}}\right],\left[R_{\mathrm{Co}}\right]$ and $\left[R_{\mathrm{Ag}}\right]$ refer to the corrosion rate of copper, cobalt and silver in $\mu \mathrm{g} \cdot \mathrm{cm}^{-2} \cdot \mathrm{h}^{-1}$ and $\mathrm{RH}$ to the relative humidity in \%. As described in Session 3.1, the temperature of the test room fluctuated, but most of the temperature ranged among 293-298 K. Therefore, we assumed that the above regression equations at $298 \mathrm{~K}$ can be used for the analysis of all data sets of corrosion rates.

Figure 10 shows the changes in thus estimated concentration of corrosive gases with exposure time. It can be supposed that the concentration of $\mathrm{H}_{2} \mathrm{~S}$ has been changed in the range of $0.01-0.25 \mathrm{ppb}$, and the concentrations of $\mathrm{SO}_{2}$ and $\mathrm{NO}_{2}$ have been changed in the range of $0.2-40 \mathrm{ppb}$. After $4100 \mathrm{~h}$ exposure, the concentrations were $0.16 \mathrm{ppb}$ for $\mathrm{H}_{2} \mathrm{~S}$, $17.7 \mathrm{ppb}$ for $\mathrm{SO}_{2}$ and $2.7 \mathrm{ppb}$ for $\mathrm{NO}_{2}$. In the previous study, ${ }^{5)}$ the corrosive gas concentration obtained by conventional analytical method for the gas sampled in the electrical control unit room after the exposure test for $4100 \mathrm{~h}$ was $<2 \mathrm{ppb}$ for $\mathrm{H}_{2} \mathrm{~S},<5 \mathrm{ppb}$ for $\mathrm{SO}_{2}$ and $15 \mathrm{ppb}$ for $\mathrm{NO}_{2}$.

Though the estimated value could not be simply compared with the chemically analyzed one at different time because of time-dependent changes in the composition of the atmosphere, it is thought that the estimated value was corresponding to the measurement one for the $\mathrm{H}_{2} \mathrm{~S}$ concentrations. For the $\mathrm{NO}_{2}$ concentration, it was considered that the estimated value was appropriate because the estimated value was the background level of the $\mathrm{NO}_{2}$ concentration typically present in the atmosphere of Japan. ${ }^{13,14)}$ However the estimated values were not corresponding to the measured 
ones for $\mathrm{SO}_{2}$ concentration. The contribution coefficients of the approximation equations were 0.97 for hydrogen sulfide, 0.78 for nitrogen dioxide and 0.64 for sulfur dioxide. ${ }^{9)}$ The reason why the estimated values for $\mathrm{SO}_{2}$ were not corresponding to the measurement ones was that the accuracy of the approximation equation was insufficient. It is thought that the estimation of the gas concentration can be improved by advancing the accuracy of the approximation equation. If considering the daily variations in the corrosive gas concentration, there exits a correspondence between the concentration estimated by the present QCM method and that obtained by the conventional method. As a result, it is thought that there is possibility that the atmospheric corrosivity can be estimated based on the monitoring of the corrosion rate with multichannel QCM sensors.

\section{Conclusions}

The corrosion rates of silver, copper and cobalt were simultaneously monitored with temperature and humidity in the electrical control unit room in a steelmaking plant. The data obtained were analyzed to utilize them for the estimation of the concentrations of the corrosive gases. The following conclusions were drawn.

(1) The fluctuation of the temperature, relative humidity, and corrosion rates were roughly distributed according to the normal probability law.

(2) The mean values of the relative humidity and the corrosion rates of the three metals, derived from the normal probability plots, can be used for estimating the concentration of $\mathrm{SO}_{2}, \mathrm{NO}_{2}$ and $\mathrm{H}_{2} \mathrm{~S}$.

(3) It is considerable that the corrosion rates of silver, copper and cobalt fluctuated since the corrosive factors like relative humidity and concentration of the corrosive gas change in the electrical control unit room.

(4) The atmospheric corrosivity will be able to estimate based on the monitoring of the corrosion rate with multichannel QCM sensors.

\section{Acknowledgments}

The authors acknowledge the invaluable advice provided by Mr. Y. Saito, Mr. M. Tanji and Mr. T. Aono of Hitachi Ltd.

\section{REFERENCES}

1) Japanese Standards Association, JIS (Japanese Industrial Standards) C0116 (1998).

2) International Electrotechnical Commission, IEC 60721-3-3 Ed. 2.2:2002 (b) (2002).

3) Japanese Electronic Industry Development Association, JEIDA-632000 (2000).

4) Instrument Society of America, ISA-S71.04-1985 Environmental Conditions for Process Measurements and Control Systems: Airborne Contaminants, Instrument Society of America (1985).

5) K. Fujii, K. Ohashi and T. Aono: Zairyo-to-Kankyo 56 (2007) 215.

6) M. Forslund, J. Majoros and C. Leygraf: J. Electrochem. Soc. 144 (1997) 2637.

7) Y. Todo, K. Kanehira, K. Kimura and J. Fukakura: Zairyo-to-Kankyo 51 (2002) 153

8) R. Schubert, B. Meagher and C. C. Chung: J. Electrochem. Soc. 142 (1995) 3157.

9) K. Fujii, K. Ohashi and T. Hashimoto: Zairyo-to-Kankyo 56 (2007) 458.

10) G. Zauerbrey: Z. Phisik. 155 (1959) 206.

11) M. Ochiai: HEAT \& ENVIRONMENT 45 (1995) 1.

12) T. Shinohara, S. Motoda, K. Nabeshima, Y. Suzuki and S. Tsujikawa: Zairyo-to-Kankyo 48 (1999) 796.

13) Japan Society of Corrosion Engineering (ed.): Corrosion Databook (Jpn.), (Maruzen, Tokyo, 1995) p. 477.

14) Chemical Society of Japan (ed.): Kagaku Binran (Ouyoukagakuhen 1) 6th Ed., (Maruzen, Tokyo, 2003) p. 402. 